\title{
A study of the relationship between the attitudes towards pornography and women amongst urban males
}

\author{
Cicilia Chettiar ${ }^{1}$, Saleha Syed ${ }^{2}$ \\ ${ }^{1}$ Assistant Professor and Head, Department of Psychology, Maniben Nanavati Women's College, Mumbai. \\ ${ }^{2}$ Postgraduate Student, Department of Psychology, Maniben Nanavati Women's College, Mumbai. \\ E-mail-ciciliachettiar@yahoo.com
}

\begin{abstract}
Background: In all settings across India, it has been noted that men view pornography off and on while some even do so on a daily basis. The study was aimed to evaluate the attitudes of men towards pornography and women in general.

Methods: The current study surveyed 208 Indian urban males to understand their attitude towards porn and women in general. It was hypothesized that there will be no correlation between men who view porn and their attitude towards women. The attitude towards porn is evaluated as either detrimental or beneficial.

Results: It was found that those who held detrimental attitude towards porn also held favorable attitudes towards women. This correlation could be indicative of the egalitarian attitude among such men. They refuse to accept the objectification of women as a good thing reflecting a healthy attitude towards women. Conclusion: The current study questions the frequently held belief that viewing porn is acceptable and has no long term impact on the well being of the individual. It must be considered that this study was conducted among the urban male population in India and could be reflective of the culture as well.
\end{abstract}

Key words: pornography, males, women, egalitarian.

(Paper Received $-24^{\text {th }}$ May 2016, Peer Review Completed $-14^{\text {th }}$ June 2016, Accepted $-17^{\text {th }}$ June 2016)

\section{INTRODUCTION}

The word pornography is derived from the Greek word pornographos, meaning literally the writing of harlots. Originally the word was used to describe the life and times of a prostitute [1]. Eventually it came to include all material, verbal or pictorial, in all forms depicting sexually explicit content. The evolution from the earliest caveman drawings to present day virtual content has been long and not without controversy. The availability of sexually explicit content in the ancient cultures appears to follow the same progression, irrespective of the culture. Initially, sexuality was celebrated, somewhere along the way it came to be condemned and now the attitude towards such content is ambivalent. The context, the individual, the culture all of these play a role in judging the phenomenon of pornography.

In some cultures, largely western democratic nations, porn is less stigmatized as compared to Eastern nondemocratic ones. But in both cases it is not without its fair share of detractors. One of the most common arguments against the use of porn is that it unfairly portrays women thereby creating in the mind of the porn viewer an unhealthy image about women. People believe that the easy accessibility of porn is what is responsible for the increasingly promiscuous behaviors in society and leads to increasing sexual assault on women. Regular consumption of pornography leads to unhealthy attitude towards women and hence it should be banned. 
Research evidence has not supported this view largely. Studies have found that viewing pornography did not have a detrimental effect on male attitude towards females [2]. Rather it was found that there was a relationship between greater negative attitudes towards women and being older; voting for a right-wing political party; living in a rural area; having a lower level of formal education; and being a man [3]. But regarding the relationship between consumers' attitudes towards women and the amount of pornography consumed, there was no connection. According to McKee, in seeking to understand how negative attitudes towards women are generated in society one should start by asking what issues might be most important, rather than beginning from the assumption that pornography is the major cause of such attitudes.

Other studies have found that pornography users held more egalitarian attitudes-toward women in positions of power, toward women working outside the home, and toward abortion - than nonusers of pornography. Use of pornography also did not affect their understanding of traditional family values. The results of this study suggest that pornography use may not be associated with gender non-egalitarian attitudes in a manner that is consistent with radical feminist theory [4].

Pornography, in the feminist view, is a form of forced sex, a practice of sexual politics, an institution of gender inequality [5]. Feminist positions can be understood as three different schools of thought when it comes to their views on pornography. Radical feminism does emphasize the patriarchal roots of inequality, but it attempts to do that by bringing about a cultural change rather than depending on the political system to bring about gender equality. Liberal feminism is more anti-censorship rather than antipornography. Finally, pro-sex feminists have defended a women's right to participate in and consume pornography. The feminist positions add strength to the pornography gender equality debate. It's not surprising that there is already so much of research attempting to find the relation between pornographic consumption, poor attitude towards women, commoditization of women and sexual assault.

The current study was undertaken to understand how the urban Indian male views women as a consequence of consuming porn. As in any other survey based design, correlation cannot mean causation. But even a basic understanding of how the two are related can lead to further research. It is high time reality is assessed based on objective evidence as compared to anecdotal ones. This study will also help understand whether the Indian culture, notorious for its current regressive stance towards women, even understands what the urban young male thinks about women.

\section{METHODOLOGY}

The hypothesis for the study is that there will be no correlation between the attitude towards porn and the attitude towards women. The survey research design was employed to note the attitude of the Urban Indian male towards the use of pornography and their overall attitude towards women. The sample consisted of 208 male Indians living in Mumbai in the age range of $18-66$ years $(M=26.22, S D=6.90)$.

The instruments used were

1. Attitude towards Pornography Scale [6]. It consists of 20 statements which are divided into two factors. One factor assesses the strength of detrimental attitudes towards porn and the other assesses the strength of beneficial attitudes towards it.

2. The Attitude towards Women Scale [7] - short version, consists of a set of twenty-five items. A high score indicates a pro-feminist, egalitarian attitude while a low score indicates a traditional conservative attitude.

\section{STATISTICAL ANALYSIS}

The descriptive statistics will help identify the mean scores of the group on both scales. Demographic variables like age and socio-economic status though collected will not be part of this analysis. The first step will be to correlate the scores obtained on both the attitude scales. The aim is to understand whether the sample used in the study find pornographic influence to be detrimental or beneficial and how this correlates to their attitudes towards women. 


\section{RESULTS}

Table 1

Mean and SD for the sample on Beneficial and Detrimental attitudes about pornography and the attitudes towards women

\begin{tabular}{|llll|} 
& $\mathrm{N}$ & Mean & $\begin{array}{l}\text { Std. } \\
\text { Deviation }\end{array}$ \\
\hline Beneficial & 209 & 40.16 & 11.67 \\
\hline Detrimental & 208 & 42.61 & 10.69 \\
\hline ATW & 209 & 71.15 & 8.08 \\
\hline
\end{tabular}

Table 2

Correlation between Beneficial and Detrimental attitudes about pornography and the attitudes towards women

\begin{tabular}{|llll|}
\hline \multicolumn{1}{|l}{} & Beneficial & Detrimental & ATW \\
\hline Beneficial & 1 & & \\
\hline Detrimental & $-.718^{* *}$ & 1 & \\
\hline ATW & .087 & $.212^{* *}$ & 1 \\
\hline
\end{tabular}

The results of table 1 show a high SD which indicated non homogeneity of the participating sample. The results from table 2 clearly show that for the participants of this study as the belief in the detrimental nature of pornography increase, so also their attitude towards women improves. This result is significant at $\mathrm{p}<0.001$ levels. Thus the null hypothesis is rejected that there will be no correlation between the attitude towards porn and towards women.

\section{DISCUSSION}

Studies indicate that men hold negative attitudes toward pornography [8]. This raises interesting questions about the relation between gender inequality and the consumption of porn. The fact that men who hold more egalitarian attitude towards women, also happen to hold detrimental beliefs about porn consumption can be shown to support traditional feminist ideas. Men who respect women and who look at them as equals may not find much positive about viewership of porn. Researches quoted this far have always talked about how there are no relation between pornography consumption and unhealthy attitude towards women. But the results of this study turn such reasoning on its head. If men, who hold women in high esteem, find viewership of pornography unhealthy, it would appear that all the arguments about the effect of porn on the status of women hold some truth.

According to a study by Ferguson \& Hartley [9], evidence for a causal relationship between exposure to pornography and sexual aggression is slim and may, at certain times, have been exaggerated by politicians, pressure groups and some social scientists.

The current study echoes the findings of probability-based sample of young Danish adults and a randomized experimental design, which investigated effects of past pornography consumption, experimental exposure to nonviolent pornography, perceived realism of pornography, and personality (i.e., agreeableness) on sexist attitudes (i.e., attitudes toward women, hostile and benevolent sexism) [10]. Further, sexual arousal mediation was assessed. Results showed that, among men, an increased past pornography consumption was significantly associated with less egalitarian attitudes toward women and 
more hostile sexism. Further, lower agreeableness was found to significantly predict higher sexist attitudes. Significant effects of experimental exposure to pornography were found for hostile sexism among low in agreeableness participants and for benevolent sexism among women. These experimental exposure effects were found to be mediated by sexual arousal.

In another study [11] designed to investigate and represent a spectrum of women's experiences with and attitudes toward pornography, five unique perspectives were arrived at. It showed that women's experiences and attitudes toward pornography cannot easily be collapsed into a unitary category of female. All women do not think about pornography in the same way nor have they had the same or similar experiences. But the current study focused only on men and hence the same result cannot be corroborated here.

A study [12] examining correlates of pornography acceptance and use within a normative (nonclinical) population of emerging adults revealed that roughly two thirds (67\%) of young men and one half (49\%) of young women agree that viewing pornography is acceptable, whereas nearly 9 out of $10(87 \%)$ young men and nearly one third $(31 \%)$ of young women reported using pornography. Results also revealed associations between pornography acceptance and use and emerging adult's risky sexual attitudes and behaviors, substance use patterns, and non-marital cohabitation values. It appears that pornography consumption has to be understood even in terms of the impact it has on the sexual attitudes and behaviors of young men and women and not merely to check for a direct causal inference as many other studies have attempted to do. Even in case of Internet pornography, exposure is greater for men than for women and hence the male sexual attitude therefore is more likely to be affected than women [13]. However this study was conducted in Taiwan an Asian country. Studies conducted in Western countries do not seem to have the same effect. For instance one of the findings of the national study of gender equality in the US examined the relationship between the circulation rates of soft-core pornographic magazines and gender equality in the 50 American states. Contrary to the hypothesis, the results showed that gender equality is higher in states characterized by higher circulation rates of pornography. This relationship is interpreted as suggesting that pornography and gender equality both flourish in politically tolerant societies [14].

However exposure to violent pornography may have a different impact even in so called tolerant societies. In an attitudes survey [15] examining pornography use, attitudes, and self-reported likelihood of rape or using sexual force. Participants revealed that use of sexually violent pornography and acceptance of interpersonal violence against women was uniquely associated with likelihood of rape or using sexual force. It was hypothesized that the specific fusion of sex and violence in some pornographic stimuli and in certain belief systems may produce a propensity to engage in sexually aggressive behavior.

The same researchers [16] used data provided by male university students, to assess the interrelationship of pornography use, anti-women attitudes, and propensity for sexual violence. The model best fitting the data was one in which use of Sexually Violent Pornography and Anti-Women Attitudes are exogenous latent variables predicting self-reported Likelihood of Rape and Likelihood of using Sexual Force, as well as selfreported history of having achieved sexual intercourse by use of Coercion and Force. A variation of this model which includes use of Nonviolent Pornography as an exogenous variable was also tested. Consistent with previous research, use of nonviolent pornography was not uniquely associated with potential or actual sexual aggression. The findings suggest the potential roles of both attitudes and sexually violent pornography in the occurrence of sexual aggression. Further, they support other research findings that suggest it is not merely exposure to sexually explicit materials, per se, but the combination of sex and violence in pornographic materials that encourages or facilitates sexual aggression.

This study has been largely restricted to Indian adult males. And although the participants included only those who have been consuming pornographic matter for a minimum of at least one year, the results cannot be generalized to the rest of the population. Possibility of social desirability may have affected the response of the participants. The type of pornographic material used has also not been taken into account. For instance content may have been available online, in print, homosexual or heterosexual, violent etc. These may affect the generalization of the results of the study. 


\title{
CONCLUSION
}

The relation between male attitude towards pornography and their attitude toward women cannot be ignored. The results of this study, when understood in light of other researches mentioned here, indicates that the connection is not superficial or direct. Rather it is moderated by demographic variables like education, socio-economic status and age of the participants. Further, there is a cultural difference in the effects of pornography and the way women are viewed. Lastly, violent pornography is very different from non-violent pornography in its impact on the attitudes towards women. All these factors need to be taken into account for future studies.

\section{REFERENCES}

1. Hyde H. Montgomery: A History of Pornography. Buckinghamshire : Great Britain ; 1964.

2. Padgett VR, Brislin-Slütz JA, Neal JA. Pornography, erotica, and attitudes toward women: The effects of repeated exposure. J Sex Research 1989;26(4):479-91.

3. McKee A. The relationship between attitudes towards women, consumption of pornography, and other demographic variables in a survey of 1,023 consumers of pornography. Int J Sexual Health 2007;19(1):31-45.

4. Kohut T, Baer JL, Watts B. Is Pornography Really about "Making Hate to Women"? Pornography Users Hold More Gender Egalitarian Attitudes Than Nonusers in a Representative American Sample. J Sex Research 2016;53(1):1-11.

5. MacKinnon CA. Sexuality, pornography, and method:" Pleasure under Patriarchy. Ethics 1989;99(2):31446.

6. Häggström-Nordin E, Tydén T, Hanson U, Larsson M. Experiences of and attitudes towards pornography among a group of Swedish high school students. Eur J Contracept Reprod Health Care 2009;14(4):277-84.

7. Spence JT, Helmreich R, AWS WS. Attitudes toward women scale (AWS). Gender roles: a handbook of tests and measures ; 1990.

8. Johansson T, Hammarén N. Hegemonic masculinity and pornography: Young people's attitudes toward and relations to pornography. J Men's Stud 2007;15(1):57-70.

9. Ferguson CJ, Hartley RD. The pleasure is momentary... the expense damnable?: The influence of pornography on rape and sexual assault. Aggr Viol Behav 2009;14(5):323-9.

10. Hald GM, Malamuth NN, Lange T. Pornography and sexist attitudes among heterosexuals. J Communication 2013;63(4):638-60.

11. Senn CY. Women's multiple perspectives and experiences with pornography. Psychol Women Quart 1993;17(3):319-41.

12. Carroll JS, Padilla-Walker LM, Nelson LJ, Olson CD, Barry CM, Madsen SD. Generation XXX pornography acceptance and use among emerging adults. J Adolesc Res 2008;23(1):6-30.

13. Chen AS, Leung M, Chen CH, Yang SC. Exposure to internet pornography among Taiwanese adolescents. Soc Behav Personality 2013;41(1):157-64.

14. Baron L. Pornography and gender equality: An empirical analysis. J Sex Research 1990;27(3):363-80.

15. Demare D, Briere J, Lips HM. Violent pornography and self-reported likelihood of sexual aggression. J Res Personality 1988;22(2):140-53.

16. Demaré D, Lips HM, Briere J. Sexually violent pornography, anti-women attitudes, and sexual aggression: A structural equation model. J Res Personality 1993;27(3):285-300.

\author{
Acknowledgements - Nil \\ Source of Funding - Nil \\ Conflict of Interest $-\mathrm{Nil}$
}

